\title{
BODY PART METONYMIES IN ACTION AND PERCEPTION FRAMES: A COGNITIVE ANALYSIS
}

Olga Isabel Diez Velasco

Universidad de La Rioja

\section{Abstract}

In Cognitive Linguistics studies on metonymy have been mainly concerned with its conceptual nature whereas its impact on grammar has generally not received much attention. However, in the last few years some authors have started to pay attention to the kind of constraints that metonymy imposes on grammar. In this paper we describe metonymies appearing within the action and perception frame focusing on their motivation and realisation patterns. Within the action frame our study centres on the ACTION FOR PROCESS mapping; and within the perception frame we posit the existence of the PERCEPTION FOR EXPERIENTIAL EVENT metonymy. Finally, the analysis reveals that both metonymies are significant both at a conceptual and at a grammatical level.

\section{INTRODUCTION}

Cognitive linguists consider both metaphor and metonymy conceptual mechanisms for reasoning and understanding. Within this trend, metaphor and metonymy are described as mappings or sets of correspondences between con- 
ceptual domains (Lakoff and Johnson, 1980; Lakoff, 1987). The difference between them lies in the nature of the domains involved: in metaphor there are two separate domains whereas in metonymy we find a domain-subdomain relationship. Although both phenomena were regarded as equally important, initially most of the work was devoted to metaphor. However, in the nineties some scholars turned their attention to metonymy (Dirven, 1993, 1999; Panther and Thornburg, 1996,1999; Ruiz de Mendoza, 1996, 1997, 1999) so that a great deal of research was carried out (c.f. the collection of articles compiled in Panther and Radden, 1999; Barcelona, 2000 and the references therein).

One of the most interesting topics in metonymy theory has been brought up by Kövecses and Radden (1998) and Radden and Kövecses (1999) who have posited the existence of some high-level principles which account for every metonymic mapping. Thus, Panther and Thornburg $(1999,2000)$ have offered detailed analyses of some of these high-level metonymies such as the POTENTIALITY FOR ACTUALITY or the EFFECT FOR CAUSE mappings. Moreover, Ruiz de Mendoza and Pérez (2001) have contended that high-level metonymies (e.g. ACTION FOR PROCESS) may place constraints on grammar. According to them, one of the phenomena where this interaction between metonymy and grammar is better observed is grammatical metonymy, which is defined as a metonymic mapping which carries syntactic consequences. Ruiz de Mendoza and Pérez offer a classification of grammatical metonymy which is based on a fundamental distinction: the scope of the grammatical transformation; that is to say, whether the change is just syntactic or whether it also affects the internal characterisation of the source domain of the metonymy. The former case, which is the main concern of our analysis, works mainly at predicate level (e.g. ACTIVITY FOR THE EVENT WHICH IS CAUSED BY IT) whereas the latter case occurs whenever a recategorization process takes place as a consequence of the metonymic mapping (AGENT FOR ACTION). Besides, we have noted that grammatical metonymy at predicate level affects the sentence differently depending on the type of ICM $^{1}$ in which it is included (namely, the Action and Perception ICMs); for this reason, our analysis will attend to this distinction and we shall describe those metonymies appearing within the action and the perception frame, paying special attention to their motivation and realization patterns.

Because of space reasons we will limit our analysis to those metonymic types which contain a body part in their instantiation. Our choice is motivated by the productivity of body parts in deriving metonymic meanings (c.f. Kövecses and

1 The notion of ICM was introduced by LAKOFF (1987) and can be defined as a domain of knowledge that results from the activity of a structuring principle. 
Szabo, 1996; Niemeier, 2000). Thus, body parts inherently play a role in our understanding of the world. We can only interact with the outer world by means of our bodies just as we perceive stimuli from the world through them. Therefore, they are likely to have a crucial role within the action and perception frames.

\section{THE ACTION FRAME}

Action ICMs include a number of participants which interact and are somehow related to the action. Thus, an action typically includes an agent, a goal (or affected entity since the action is directed at it), a beneficiary and an instrument. Most of these participants are optional (i.e. they need not appear in all cases). However, one of them is compulsory for the definition of this ICM: the agent. The reason is that the agent is the only participant that can be in control of an action and actions are, by definition, controlled states of affairs (or SoAs). Accordingly, every action must have an agent as the following example illustrates:

(1) Nick tightened his fingers with a menacing precision.

Example (1) represents a prototypical action where Nick is the agent and fingers the goal. Note that Nick is in control of the SoA since he can decide whether it will take place or not (i.e. he can choose whether to tighten his fingers or not). But what if the elements in an action frame combine while excluding the agent?

(2) Nick's fingers tightened with a menacing precision.

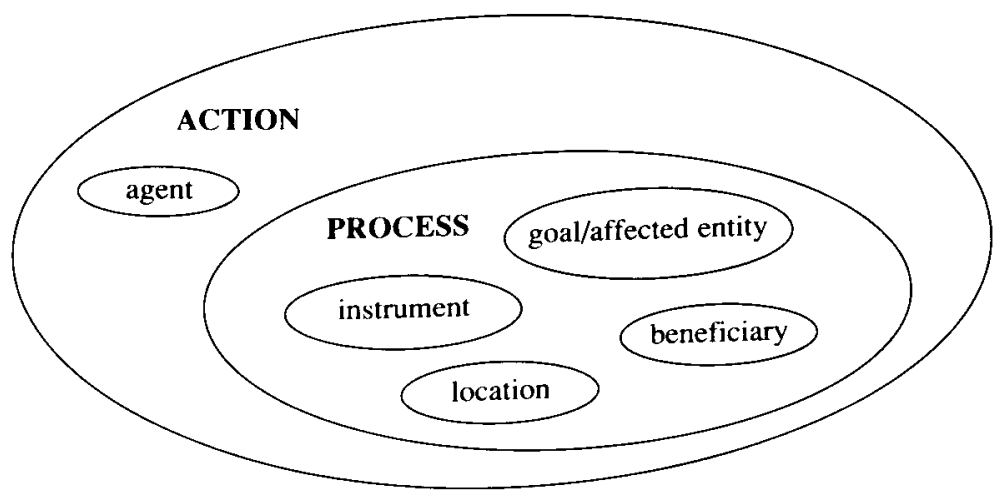

Figure 1. The Action Frame. 
Obviously, the result can never be an action since in (2) the fingers are not in control of the SoA; it is a process according to Dik's (1989) labelling (i.e. a [-control] [+dynamic] SoA). The relationship between events and actions is better observed in the following figure where the domain-subdomain relation that holds between them is evident:

At first sight, the fact that (2) is a process does not necessarily mean that it includes any metonymic mapping. However, a closer look at this sentence shows that this is not the case and that it is a grammatical metonymy.

To begin with, according to Dik's (1989) typology ${ }^{2}$, (2) represents a process (that is to say, a non-controlled and dynamic SoA) whereas (1) is an action (i.e. a controlled and dynamic SoA). This means that control is the only distinguishing feature between them. However, (2) is not completely non-controlled: we understand that someone controls the SoA although this is not explicitly stated (e.g. there is no doubt that Nick is the agent in (2)). Thus, in these sentences we are using an action metonymically to refer to a process. Ruiz de Mendoza and Pérez (2001) have called this high-level metonymy ACTION FOR PROCESS. As a result of this mapping, the controller entity loses its prominence and fingers achieves a much more relevant role since the whole process is focused on them.

Once we have shown the existence of this metonymic mapping, we will study the way it takes place and the syntactic consequences it has for the organization of the clause. Consider the following examples:

(a) His lips brushed against her cheek.

(b) He brushed his lips against her cheek.

(3a) is another example of an ACTION FOR PROCESS metonymy and (3b) is its non-metonymic counterpart. When comparing both of them the first thing we observe is that the position of the agent is occupied by the affected entity in (3a). This is a consequence of the transformation of an action into a process (see figure 2). Since a process lacks control, it cannot assign the semantic function «agent». Thus, the first argument position is left vacant. But English sentences must have a subject so that the affected entity, which occupies the second argument position in ( $3 \mathrm{~b})$, is raised to the first argument position. Secondly, this metonymy prompts a valency re-

2 Dik (1989) puts forward a classification of SoAs in which he distinguishes four main types (i.e. actions, processes, positions and states) which are defined according to the parameters of [ \pm control] and [ \pm dynamic.] 


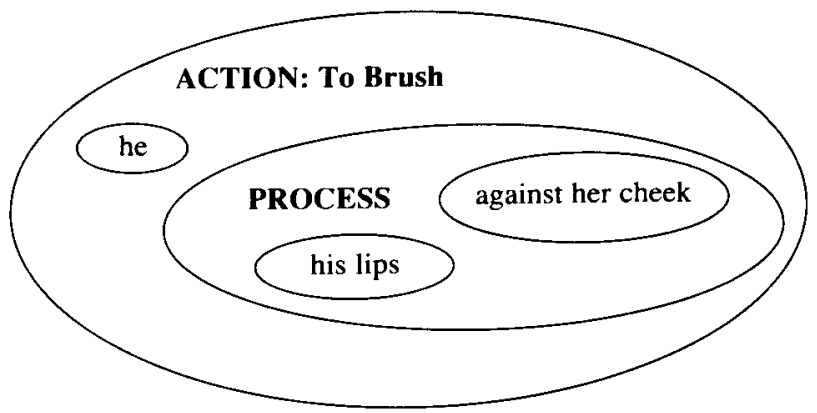

Figure 2. His lips brushed against her cheek.

duction ${ }^{3}$ of the predicate so that the verb to brush, which is typically transitive, behaves intransitively in example (3a).

We have contended that thanks to this metonymic mapping the affected entity (lips) acquires a greater degree of prominence. Let us explain the way it occurs. As a consequence of the valency reduction, lips, which is the only argument position of the predicate, is raised to the subject position. This position is considered the most privileged one within the clause by numerous authors (c.f. Dik, 1989; Langacker, 1991; the latter explains transitive sentences by means of the figure/ground segregation where the subject corresponds to the figure (the prominent part) and the direct object to the ground). Hence, by means of the metonymic mapping the affected entity acquires the most prominent place in the clause; in other words, the metonymy serves to upgrade a nonfirst argument to the most privileged position in the clause (i.e. the subject position). Therefore, this metonymic mapping is a device for perspectivising a situation the same way the passive voice is.

Besides, this metonymic mapping is also motivated by economy principles as can be easily observed when comparing (3a) and ( $3 b$ ). The latter example introduces one further argument to the representation of the SoA. Thus, in (3b) two arguments are compulsorily needed, whereas (3a) is a one-place predicate because the reduction of one of the arguments of the predicate is made possible by the metonymic link. This is what makes (2) and (3a) cases of grammatical metonymies, i.e. that the metonymy has syntactic consequences for the sentences in which it appears.

${ }^{3}$ DIK (1989) defines valency reduction as a procedure to form derived predicates which takes place when one argument position is removed from a predicate. 
This type of grammatical metonymy is a very valuable resource for converting transitive sentences into intransitive ones. Moreover, it lays bare the motivation of a phenomenon which has been analyzed by several authors (Dik, 1989; Levin, 1993). These authors, however, have just offered a more or less detailed description of it in terms of valency reduction (Dik, 1989) or in terms of the causative-inchoative alternation (Levin, 1993) but they have failed to understand the metonymic motivation that underlies this process.

Nevertheless, it is important to note that we are not postulating that for every case of valency reduction there exists a metonymy which motivates the reduction of an argument position. This only holds true for the shift from a [+control] SoA to a [-control] SoA. Further analyses are needed to find out whether there is a metonymic motivation for every pattern of valency reduction.

A variation of this type of metonymy is found in (4):

(4) Her arm rose and fell back on the bedclothes.

As in the previous cases, arm has not the semantic function 'agent', not being in control of the SoA (it is the person who is in control of it). However, there is a basic difference between this predicate and the one in (3a); namely, while in (3a) the metonymy has caused the reduction of one of the argument positions of the predicate, in (4) to rise is a one-place predicate so that there is no valency reduction at all. It could be wrongly argued that the metonymy in (4) is only conceptual since there is no valency reduction, and therefore, it brings about no syntactic consequences for the rest of the clause. But the comparison of (4) and (5) throws some new light and shows that this is not the case:

\section{(5) Arthur raised an arm in greeting}

Thus, to raise and to rise represent the same SoA from different perspectives and work in complementary distribution, the former accounting for the transitive uses and the latter for the intransitive ones. This suggests that a literal version of (4) should employ to raise instead of to rise (e.g. She raised her arm). Hence, the metonymy causes the reduction of one argument of the predicate; but, the existence of the verb to rise makes impossible the use of the verb to raise intransitively. As a consequence, the change of verb becomes compulsory in order to avoid ungrammaticality (i.e. ${ }^{*} \mathrm{Her}$ arm raised). Therefore, we are dealing again with a grammatical metonymy: the metonymic mapping causes the shift from the verb to raise in the literal version to the verb to rise in the one containing the metonymy. On the whole, the change of verb motivated by a metonymic mapping is an uncommon 
phenomenon simply because these alternations (e.g. to raise/to rise) are rare in English.

In all the previous examples, there was an SoA standing for another SoA. However, this is not the only pattern available within the action frame, as evidenced in (6) and (7):

(6) His other hand retrieved the rose

(7) His thumb touched her cheek gently

In (6) and (7) we find instantiations of the INSTRUMENT FOR AGENT mapping. Thus, the actions of retrieving and touching are not performed by hand and thumb, respectively, but by a person; that is to say, the instrument, which in these sentences coincides with the body part more closely connected to the action, occupies the function assigned to the agent.

This metonymic type differs from the other cases of metonymy studied so far in the fact that the metonymic sentences are transitive. Hence, (6) and (7) have the same number of argument positions as their non-metonymic counterparts below. This means that the INSTRUMENT FOR AGENT metonymy cannot motivate a valency reduction of the predicate:

(8) He retrieved the rose with his other hand

(9) He touched her cheek gently with his thumb

Once more, it could be argued that these mappings are not cases of grammatical metonymy since there seems to be no syntactic consequence for the organisation of the clause. However, a closer look at these four sentences reveals some interesting aspects of this metonymic type. Firstly, the comparison shows that (8) and (9) include both the agent and the instrument, and that if the latter were removed, important meaning would be lost. Secondly, the metonymy allows the shift of the instrument from its canonical position to the place left by the agent. Thus, the metonymic mapping provokes the disappearance of one element of sentence structure (i.e. the agent).

The INSTRUMENT FOR AGENT metonymy emphasises the role of the instrument of the action by placing it higher than the second argument of the predicate. Thus, by means of this metonymy, the instrument is promoted to the most privileged position of the clause, and therefore, becomes an argument (the first argument). Once more, this grammatical metonymy is a tool English speakers have to represent a SoA from a different perspective.

We suggest that the motivation for the high frequency of this metonymic type in English is related to our folk-model understanding of the person as a com- 
posite of different functional parts. Thus, we tend to conceive each part of the person as in charge of certain activities for which its function is specially relevant. However, this instrumental function does not canonically occupy a privileged position in the clause, which is evidenced by the fact that it is not given argument status by some authors (e.g. Dik, 1989). In consequence, the metonymy is only a way to increase its prominence by promoting the instrument to a subject position.

\section{THE PERCEPTION FRAME}

Perceptions are concerned with our experiences about the world. Their relevance in everyday life has been postulated by author such as Kövecses and Radden (1998) and Langacker (1987). These scholars have argued in favour of their distinct nature from actions, although they admit that perceptions may resemble actions in some respects. The main participants of a perception frame are the experiencer and the phenomenon. The former, as its name suggests, is the sentient being that senses or experiences while the latter is the object of the perception (i.e. what is sensed). Clearly, there exist more participants in the frame but they are not compulsorily needed in every case. More interestingly, this frame also includes an affected entity, which is the entity most closely connected to the perception. The affected entity may have different roles in the clause. For instance, in Suddenly, I felt a sharp pain in my chest, «the chest» is the affected entity since the perception is primarily concerned with it, in I felt my stomach queasy, «my stomach» is the affected entity and in I feel tired the experiencer (i.e. "I») coincides with the affected entity.

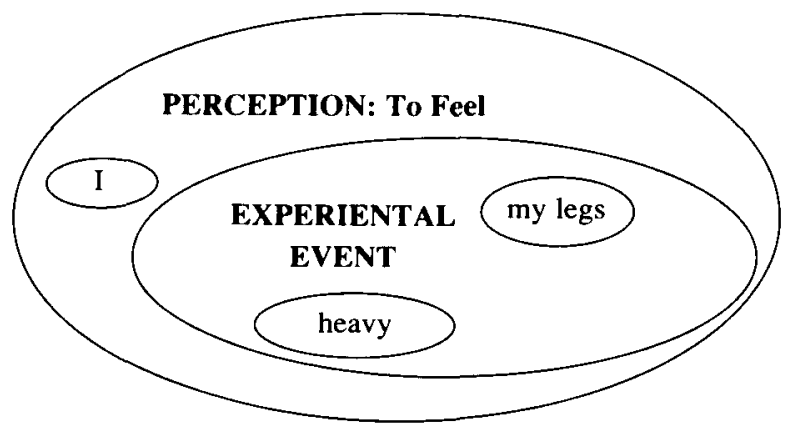

Figure 3. My legs feel heavy. 
Whenever the experiencer and the affected entity are separate, there exists the possibility that the participants of a perception rearrange while leaving the experiencer apart:

(10) My legs feel heavy

This situation parallels the ACTION FOR PROCESS metonymy as evidenced in the following diagram:

As was the case within the action frame, a compulsory element (i.e. the experiencer) is excluded from the frame so that it is no longer a perception; what we have is an experiential event, which stands for the perception. Note that in (10) it is clear that the experiencer is $I$ as the non-metonymic version of the sentence shows:

(11) I feel my legs heavy.

Therefore, we can postulate the existence of the PERCEPTION FOR EXPERIENTIAL EVENT metonymy. It takes place whenever (a) the experiencer and the affected entity do not coincide and (b) the experiencer of a perception is left apart while its place is occupied by the affected entity. Three different patterns of PERCEPTION FOR EXPERIENTIAL EVENT mappings can be distinguished regarding the role of the affected entity. The rest of this section will be devoted to analysing in depth the different ways this metonymy works, its implications and motivations. The first one is illustrated in the following example:

(12) When her lungs felt as if they would burst, Mary finally reached double gates.

In (12) the lungs are presented as living entities capable of feeling and having perceptions since they are the experiencer, occupying the subject position. However, example (12) portrays a very different situation, namely, Mary is so tired that she feels that her lungs are going to burst. Hence, the experiencer is not the lungs, but the person. Besides, lungs, and by extension any body part, can never be the experiencer because they are not endowed with the faculty of having perception; only living creatures are. What we find in this example is an instantiation of the PERCEPTION FOR EXPERIENTIAL EVENT metonymic mapping. The way this metonymy works is better observed when we compare example (12) with the following example:

(13) She ran until she felt as if her lungs would burst. 
Example (12) and (13) can be said to offer the same situation as far as the subordinate clause (in bold typeface) is concerned. The only difference between them is that (13) is a perception, whereas in (12) the experiencer is not overtly stated and the affected entity (i.e. the lungs) occupies its place. Hence, a metonymic mapping is needed for the correct interpretation of the sentence as a perception (i.e. in the real world lungs do not feel). In short, in (13) the SoA is presented as a perception where no part is given prominence over the rest while in (12) a metonymic mapping takes place in order to highlight the role of the lungs.

As far as the grammar is concerned, the comparison of these two sentences is also useful. Firstly, as a result of this metonymic mapping the affected entity which works as the subject of an embedded clause (lungs) is promoted to the subject position of the main clause; i.e. it achieves a more prominent position in the clause. In this respect, the PERCEPTION FOR EXPERIENTIAL EVENT metonymy is not different from the ACTION FOR PROCESS mapping.

Secondly, it is interesting to note that in the non-metonymic version both the experiencer and the affected entity (the person and the lungs) are included as was the case with the examples studied within the action ICM. However, a closer look reveals an important difference between the metonymic mapping in (12) and those of the previous section; namely, example (12) makes reference to the concept of lung twice: one in the subject position of the main clause and the other as a pronominal form in its canonical place (the subject of the subordinated clause). This means that the metonymic mapping does not call for the deletion of the subject position of the subordinate clause. Furthermore, this deletion of the pronoun would result in an ungrammatical sentence (e.g. ${ }^{*}$ Her lungs felt as if they would burst). There are two possible reasons for this. The former is that this position cannot be left vacant because English sentences must always have a subject. Therefore, although lungs is promoted to the main clause, its place in the embedded clause is occupied by a pronoun with which lungs is correferential. The latter is that in contrast to previous cases where we were dealing with simple clauses, now she and lungs are placed in different clauses in the literal version. As a result, the distance between them is greater so that the metonymic mapping cannot motivate the elimination of one element which is in a different clause and only provokes its transformation into a pronominal form (i.e. they) in order to avoid redundancy. Thus, a metonymic mapping cannot cause valency reduction beyond the limits of the clause. We believe that this latter hypothesis is the correct one. This is substantiated by the analysis of other cases where the affected entity occupies a non-subject position in the embedded clause and remains as a pronominal form, as will become clear when we study it.

Finally, just to note that her lungs would burst is a metaphoric way of expressing exhaustion. First, the lung is conceived as a machine. When a machine 
works beyond its possibilities it ends up bursting or exploding. Second, our knowledge about machines interacts with our knowledge about the stereotypical symptoms of exhaustion ${ }^{4}$ : one of the physiological effects of running or making strenuous physical effort is that we breathe quicker.

The second pattern found can be observed in the following example:

(14) Her chest felt as if frantic hands were hammering it.

This is a very interesting example which shows the pervasiness of the metonymic and metaphoric phenomena in everyday language as it contains three metonymic mappings and a metaphoric one. First, we shall deal with the metonymy relevant for our present discussion: the PERCEPTION FOR EXPERIENTIAL EVENT mapping; and then we shall sketch out briefly the other ones. As in the previous case, the chest as a body part is not a proper experiencer so the metonymic mapping is needed in order to make sense of this sentence. At first sight it may seem that this metonymy is identical to the previous one; but, this is not the case as evidenced by the rewriting of (14) where the metonymy is avoided:

(15) She felt as if frantic hands were hammering her chest.

The comparison between (14) and (15) shows that the original place for «chest» is the direct object position of the embedded clause. Thus, although both in (12) and (14) the metonymy allows the movement of the affected entity (the body part) from the embedded clause to the main one, the position of the affected entity in the embedded clause is different: the subject in (12) and the direct object in (14).

When dealing with the previous metonymic pattern where the affected entity was the subject of the embedded clause, we noted that the main difference between this metonymy and those studied within the action frame was related to the way the grammar of the sentence was affected by the metonymic mapping; namely, in the latter the result of the metonymic mapping was the reduction of the second argument of the predicate or of one of its satellites whereas in the former the metonymic mapping does not trigger the deletion of any element of the sentence but its conversion into a pronoun. Furthermore, we offered two possible answers to account for this difference and supported the sec(1990).

4 On the way physiological phenomena help us in conceptualising emotions, see Kövecses 
ond one (i.e. a metonymy cannot produce the deletion of an element beyond the boundaries of the clause). This metonymy helps to confirm our hypothesis. Let us explain the reasons why.

Firstly, we have pointed out that by means of the PERCEPTION FOR EXPERIENTIAL EVENT metonymy the direct object of an embedded clause is raised to the subject position of the main clause. Secondly, we have seen that in similar grammatical metonymies (e.g. the ACTION FOR PROCESS mapping) where we dealt with simple clauses (c.f. example (2)) the metonymy may cause the reduction of an argument position (i.e. the direct object). Then, it is obvious that the deletion of the direct object of a transitive sentence is possible in English. Thus, the only difference between (2) and (14) is that the distance between the experiencer and the affected entity is greater in the latter because they are in different clauses as put forward in the second hypothesis.

It may be argued that they also differ in the fact that one metonymy takes place within an action and the other within a perception, but in the discussion of the last pattern, we shall see that this is not a relevant parameter.

The other metonymies of (14) are found in frantic hands and to hammer. Hand is the source domain of a grammatical metonymy (INSTRUMENT FOR AGENT) as it is not a hand but a person that carries out the action with his hands. In hammer, we find another grammatical metonymy where the instrument employed in the performance of an action metonymically stands for the whole action. In this case the metonymy involves a word form conversion since a category change (from noun to verb) follows the metonymic mapping.

Regarding the metaphor, the situation is similar to the one found in (12) where two metaphors interact. First, the chest is conceived as an object that someone is hitting repeatedly. And this is used to describe a frightened person because one of the physiological effects of fear is that the heart beats stronger or faster and it seems to hit against the chest (c.f. footnote 4).

Finally, the last metonymic type of this group is illustrated in the following example:

(16) Juliet's throat felt dry.

There is no doubt that in (16) the throat cannot experience anything because it is Juliet that has a feeling concerning her throat. Example (16) contains another instantiation of the PERCEPTION FOR EXPERIENTIAL EVENT metonymic mapping where the throat (the affected entity) is not the experiencer as its non-metonymic version evidences: 


\section{(17) Juliet felt her throat dry}

Following Dik (1989: 165-169), in example (17) throat is an argument of an adjectival predicate. Thus, by means of this metonymy the argument of an adjectival predicate is promoted to the first argument position of the verbal predicate (c.f. 16). In addition, the comparison of (16) and (17) reveals an important feature of this metonymy: the metonymic mapping allows the deletion of the affected entity from its original place (i.e. the argument of the adjective). Furthermore, its repetition or transformation into a pronoun would result in an ungrammatical sentence (e.g. *Juliet's throat felt her throat/it dry). Since this last example differs from the previous PERCEPTION FOR EXPERIENTIAL EVENT metonymies studied in being a simple sentence, it proves that the perception frame does not pose any restriction on the deletion of a clausal element as a result of a grammatical metonymy: in (16) the metonymy occurs within a perception frame and the deletion is compulsory. Therefore, this pattern further substantiates the hypothesis that the scope of action of a grammatical metonymy is the clause.

To sum up, all the metonymic patterns distinguished within the perception frame coincide in being motivated by a search for prominence; to be more precise, by means of these metonymic mappings the affected entities which are placed in a non-privileged positions are raised to the more prominent place in the sentence (i.e. the subject position of the main clause).

\section{Conclusion}

In this paper we have studied some high-level metonymies by paying special attention to the frame within which they take place. The analysis has revealed that all the high-level metonymies found in our research are significant both at a conceptual and at a grammatical level; that is to say, the metonymy has consequences for the general organization of the clausal structure. This has shown the relevance that a phenomenon such a metonymy may have for the adequate understanding of some grammatical issues such as valency reduction.

Moreover, by making a parallel with the ACTION FOR PROCESS mapping we have posited the existence of the PERCEPTION FOR EXPERIENTIAL EVENT metonymy, which accounts for those cases in which the experiencer of a perception is not overtly expressed. We have also observed that this metonymy can be realized according to three different patterns. Besides, the study of these three patterns has provided us with enough evidence to postulate that the scope of action of a grammatical metonymy is within the boundaries of the clause. 
Finally, we conclude that the basic motivation underlying the metonymies found in our analysis is highlighting the role of the body part. Thus, all the metonymic mappings coincide in locating the body part in a more privileged position than it originally had in the non-metonymic version.

\section{REFERENCES}

Barcelona, A (ed.) (2000): Metaphor and Metonymy at the Crossroads, Berlin/ New York: Mouton de Gruyter.

Dik, S. C. (1989): The Theory of Functional Grammar, Vol.1: the Structure of the Clause. Dordrecht: Foris.

DiRVEN, R. (1993): «Metonymy and metaphor: different mental strategies of conceptualisation». Leuvense Bijdragen 82: 1-25.

DIRVEN, R. (1999): "Conversion as a conceptual metonymy of event schemata». Panther, K. and Radden, G. (eds.) Metonymy in Language and Thought. Amsterdam/Philadelphia: John Benjamins. 275-288.

HallidaY, M. A. K. (1994): An Introduction to Functional Grammar. London: Edward Amold. 2nd. de.

KöveCSES, Z. and SZABO, P. (1996): «Idioms: A view from Cognitive Semantics». Applied Linguistics, Vol. 17-3: 326-355.

KöVECSES, Z. and RADDEN, G. (1998): «Metonymy: developing a cognitive linguistic view». Cognitive Linguistics 9-1: 37-77.

KöVECSES, Z. (1990): Emotion Concepts, New York: Springer-Verlog.

Lakoff, G. and Johnson, M. (1980): Metaphors We Live By. Chicago: The University of Chicago Press.

LAKoff, G. (1987): Women, Fire, and Dangerous Things: What Categories Reveal about the Mind. Chicago: The University of Chicago Press.

LANGACKER, R. W. (1987): Foundations of Cognitive Grammar. Vol. 1: Theoretical Prerequisites. Stanford: Stanford University Press.

LANGACKer, R. W. (1991): Foundations of Cognitive Grammar. Vol 2: Descriptive Application. Stanford: Stanford University Press.

LeVIN, B. (1993): English Verb Classes and Alternation: a Preliminary Investigation. Chicago \& London: The University of Chicago Press.

Niemeier, S. (2000): «Straight from the heart - Metonymic and metaphorical explorations». Barcelona, A (ed.). Metaphor and Metonymy at the Crossroads, Berlin/ New York: Mouton de Gruyter. 195-214.

Panther, K. and RAdDen, G. (eds.) (1999): Metonymy in Language and Thought. Amsterdam/ Philadelphia: John Benjamins.

PANTHer, K. and ThORnburg, L. (1996): «Metonymic and indexical inferencing in conversation». Fifth International Pragmatics Conference. Mexico. 
PANTHER, K. and Thornburg, L. (1998): «A cognitive approach to inferencing in conversation", Journal of Pragmatics 30, 755-769.

Panther, K. and Thornburg, L. (1999): «The Potential for Actuality metonymy in English and Hungarian». PANTHER, K. and RADDEN, G. (eds.): Metonymy in Language and Thought. Amsterdam/ Philadelphia: John Benjamins. 333-359.

Panther, K. and Thornburg, L. (2000): «The EFFeCt FOR CaUse metonymy in English grammar». Barcelona, A (ed.). Metaphor and Metonymy at the Crossroads, Berlin/ New York: Mouton de Gruyter. 215: 232.

Radden, G. and Kövecses, Z. (1999): «Towards a theory of metonymy». Panther, K. and RADDEN, G. (eds.) Metonymy in Language and Thought. Amsterdam/ Philadelphia: John Benjamins. 17-60.

RUIZ DE MENDOZA IBÁÑEZ, F. J. (1996): «Understanding through metonymy: the role of metonymy in communication and cognition». PEnAs, B. (ed.) The Pragmatics of Understanding and Misunderstanding. University of Zaragoza, Servicio de Publicaciones. 197-208.

Ruiz DE MENDOZA IBÁNé, F. J. (1997): «Metaphor, metonymy and conceptual interaction». Atlantis Vol.19, 1, 281-295.

RUIZ DE MENDOZA IBÁNEE, F. J. (1999): «From semantic underdetermination via metaphor and metonymy to conceptual interaction» Essen: LAUD №.492.

Ruiz de Mendoza IbáNez, F. J. and Pérez Hernández, L. (2001): «Metonymy and the grammar: motivation, constraints and interaction». Language \& Communication, 21-4: 321-357. 